\title{
ANALISIS KEBERLANJUTAN PENERAPAN PENGELOLAAN TANAMAN PADI SECARA TERPADU TERHADAP DIMENSI EKOLOGI DAN TEKNOLOGI DI KABUPATEN MUSI RAWAS
}

\author{
$1^{*}$ Novianto \\ ${ }^{1 *}$ Program Studi Agroteknogi Fakultas Pertanian, Universitas Musi Rawas \\ Jl. Pembangunan Kompleks Perkantoran Pemkab Mura, Lubuklinggau 31628 \\ * Coresponden/author: Telp. (0733) 451744 \\ email: : noviantorahmad4@gmail.com
}

\begin{abstract}
ABSTRAK
Penelitian ini bertujuan adalah untuk menilai dan menelahah atribut dalam dimensi ekologi dan teknologi yang berpengaruh terhadap keberlanjutan pengelolaan tanaman padi secara terpadu melalui program SL-PTT dalam pengembangan tanaman padi sawah di tingkat petani dalam upaya meningkatkan produktivitas secara berkelanjutan, besarnya peluang tingkat keberlanjutan terhadap penerapan pelaksanaan program SL-PTT di Kabupaten Musi Rawas melalui diujicoba menggunakan metode Multi Dimensional Scaling (MDS). Data yang digunakan data primer dan data sekunder. Analisis Status Keberlanjutan Penerapan Program Sekolah Lapang Pengelolaan Tanaman Terpadu di Kabupaten Musi Rawas dengan menggunakan Multidimensional Scaling (MDS) dengan mengetahui atribut dua dimensi yang dianalisis, yang terdiri dari dimensi ekologi dan teknologi. Hasil analisis RAP- Program SL PTT multidimensi dengan menggunakan metode MDS menghasilkan nilai IKB yaitu, dimensi ekologi baik atau sangat berkelanjutan dengan nilai IKB 75.90 dan dimensi teknologi cukup berkelanjutan dengan nilai IKB 73.25, pada skala sustainibilitas 0 100 sebanyak 21 atribut. Sedangkan berdasarkan hasil analisis RAP-Program SL-PTT menunjukan hubungan keterkaitan antar dimensi yang diukur dengan Squarred Correlation $\left(\mathrm{R}^{2}\right)$ sebesar 0.930, ini mengindikasikan bahwa keterkaitan antara dimensi mencapai $95 \%$ atau sangat kuat.
\end{abstract}

Kata Kunci : Indeks dan Status Keberlanjutan, Pengelolaan Tanaman Padi Terpadu. 


\section{BAB I}

\section{PENDAHULUAN}

permasalahan, mengambil keputusan dan menerapkan teknologi yang sesuai dengan kondisi sumberdaya setempat secara sinergis

Tanaman pangan memiliki peranan yang dan berwawasan lingkungan sehingga sangat penting untuk memenuhi kebutuhan usahataninya menjadi efisien, masyarakat terutama komoditi padi, dimana setiap berproduktivitas tinggi dan berkelanjutan tahunnya kebutuhan tersebut semakin meningkat (Departemen Pertanian, 2008). Berdasarkan seiring dengan pertambahan jumlah penduduk. Berdasarkan data produktivitas padi dari Badan Pusat Statistik untuk tingkat Nasional mengalami peningkatan ditahun 2020 rata-rata sebesar 55.160.548,20 ton per tahun dari tahun berdasarkan tingkat kehijauan warna daun, sebelumnya, sedangkan data produksi di tingkat pemupukan organik, pengairan berselang dan Provinsi, dimana provinsi Sumatera Selatan juga pengendalian gulma masuk dalam kategori mengalami peningkatan dengan data adopsi sedang artinya adopsi teknologi belum produktivitas padi sebesar 2.696.877,46 ton per terserap maksimal.

tahun (Badan Pusat Statistik, 2020).

Pertanaman di areal SL-PTT padi

Pemerintah melakukan strategi dalam mampu menaikan target produksi sebesar 1-2 upaya agar pembangunan pertanian pangan yang ton / ha dan di areal LL dalam SL-PTT komprehensif dan terpadu adalah kunci menuju swasembada pangan berkelanjutan adalah melindungi dan memberdayakan masyarakat petani dengan cara perluasan lahan, subsidi pertanian (modal, benih, obat-obatan, dan pupuk), penyuluhan pertanian, pembangunan infrastruktur (jalan, listrik, dan irigasi) dan teknologi pertanian, digunakan sebagai unit LL akan mendapat mempermudah dalam proses pemasaran produk bantuan benih, pupuk Urea, NPK dan pupuk pertanian serta semua pihak ikut terlibat dalam Organik. (Direktur Jenderal Tanaman Pangan, pengembangan pertanian pangan nasional, mulai 2012).

dari lembaga pemerintah, lembaga pendidikan dan penelitian, lembaga swadaya masyarakat (LSM) dalam membantu petani mengatasi permasalahan yang ada di lapangan. (Badan Pengkajian Teknologi Pertanian, 2011).

Padi adalah salah satu bahan makanan yang mengandung gizi dan penguat yang cukup baik bagi tubuh manusia, sebab didalamnya terkandung bahan yang mudah Dat diubah menjadi energi atau disebut makanan penelitian ini dengan menggunakan Observasi energi. Untuk mencapai tujuan swasembada Lapangan dan mengambil Data Primer yaitu beras tersebut dengan meningkatkan dengan memberikan kusioner kepada enam program-program pertanian sebelumnya. kelompok tani yang tergabung dalam tiga Program-program pertanian tersebut, Gabungan Kelompok Tani (Gapoktan) yang telah diantaranya intensifikasi yakni memanfaatkan mengikuti SL-PTT di tiga Kecamatan yaitu padi unggul, optimasi lahan berupa membuka Kecamatan Tugumulyo, Kecamatan Purwodadi lahan tidur, dan rehabilitasi yakni dan Kecamatan Sumberharta di Kabupaten Musi meningkatkan teknologi. Salah satu strategi Rawas dengan jumlah responden atau pelaku meningkatkan teknologi. Salah satu strategi usaha sebanyak 30 petani. Data Sekunder yaitu dalam upaya pencapaian produktivitas dengan wawancara langsung dengan pihak usahatani padi adalah penerapan inovasi pemerintah yang terlibat dalam program SL-PTT teknologi yang sesuai dengan sumberdaya dan didukung dengan dokumen-dokumen yang pertanian di suatu tempat (spesifik lokasi). ada di Instansi terkait beserta steakholder yang Teknologi usahatani padi spesifik lokasi turut mendukung program SL PTT.

tersebut dirakit dengan menggunakan Seluruh data dari atribut yang pendekatan Sekolah Lapang Pengelolaan dipertimbangkan dalam penelitian ini selanjutnya Tanaman Terpadu (SL-PTT).

Sekolah Lapang Pengelolaan Tanaman dan Sumberdaya Terpadu (SL-PTT) Suatu tempat pendidikan non formal bagi petani

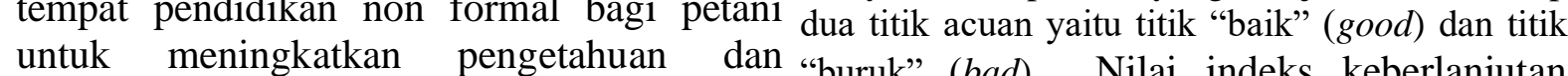
ketrampilan dalam mengenali potensi, setiap dimensi dikaji dan dianalisis. Setiap menyusun rencana usahatani, mengatasi dianalisis secara multidimensi untuk menentukan titik yang mencerminkan posisi keberlanjutan penerapan pelaksanaan SL-PTT di masing-masing wilayah kelompoktani yang dikaji relatif terhadap 
atribut pada masing-masing dimensi skor yang merupakan nilai indeks diberikan skor berdasarkan Scientific keberlanjutan setiap dimensi dapat dilihat judgment dari pembuat skor. Adapun nilai pada Tabel 1.

Tabel 1. Kategori status keberlanjutan berdasarkan nilai indeks

\begin{tabular}{cc}
\hline Nilai Indeks & Kategori \\
\hline $0-24.99$ & Buruk \\
$25-49,99$ & Kurang \\
$50-74.99$ & Cukup \\
$75-100$ & Baik \\
\hline
\end{tabular}

BAB III

HASIL DAN PEMBAHASAN untuk menilai keberlanjutan (Nurmalina, R, 2008).

Sedangkan untuk mengevaluasi error

Berdasarkan hasil analisis dalam proses ordinasi dilakukan dengan keberlanjutan dari dimensi aspek ekologi dan analisis Monte Carlo. Analisis Monte Carlo teknologi dalam penerapan SLPTT di akan menghasilkan nilai stress, nilai stress Kabupaten Musi Rawas, data yang diperoleh dapat diterima jika nilainya kurang 25\%, dari survei lapang diolah dengan (Thamrin dkk. 2007).

menggunakan metode Multidimensional Berdasarkan hasil analisis Monte Scaling (MDS) yang disebut dengan metode Carlo diperoleh nilai stress sebesar 20.56 RAP-RICE yang merupakan adaptasi dari sehingga tingkat kesalahannya dapat diterima. metode RAPFISH yang telah digunakan Hasil analisis Monte Carlo dapat dilihat pada

Tabel 2.

Tabel 2. Hasil analisis Monte Carlo penentuan Indeks Keberlanjutan Penerapan Program Sekolah Lapang Pengelolaan Tanaman Terpadu di Kabupaten Musi Rawas

\begin{tabular}{lcccc}
\hline \multicolumn{1}{c}{ Dimensi } & MDS & Monte Carlo & Stress (\%) & $\begin{array}{c}\mathrm{R}^{2} \\
\text { (Squarred } \\
\text { Correlation) }\end{array}$ \\
\hline Ekologi & 75.90 & 79.20 & 19.03 & 0.943 \\
Teknologi & 73.25 & 78.51 & 19.01 & 0.933 \\
\hline
\end{tabular}

Analisis RAP-Program SL-PTT dan memberikan pengaruh terhadap keberlanjutan analisis leverage pada setiap dimensi pada dimensi ekologi terdiri dari (1) hasilnya sebagai berikut: ketersediaaan air saluran irigasi, (2) 3.1. Keberlanjutan Penerapan Program menggunakan pupuk kimia, (3) puso padi

Sekolah Lapang Pengelolaan Tanaman akibat banjir, (4) puso padi akibat kekeringan,

Terpadu di Kabupaten Musi Rawas (5) peledakan hama pada saat musim tanam,

Dimensi Ekologi

(6) pengendalian gulma menggunakan herbisida, (7) pengendalian HPT dengan

Hasil analisis menunjukkan indeks pestisida dan (8) kesuburan tanah. keberlanjutan Penerapan Program SL-PTT Berdasarkan hasil analisis leverage dimensi ekologi di tingkat Kabupaten adalah keberlanjutan RAP-Program SL PTT dapat 75,90, dengan kategori baik/sangat dilihat pada Gambar 4.3. berkelanjutan dengan atribut-atribut

\section{Leverage of Attributes}

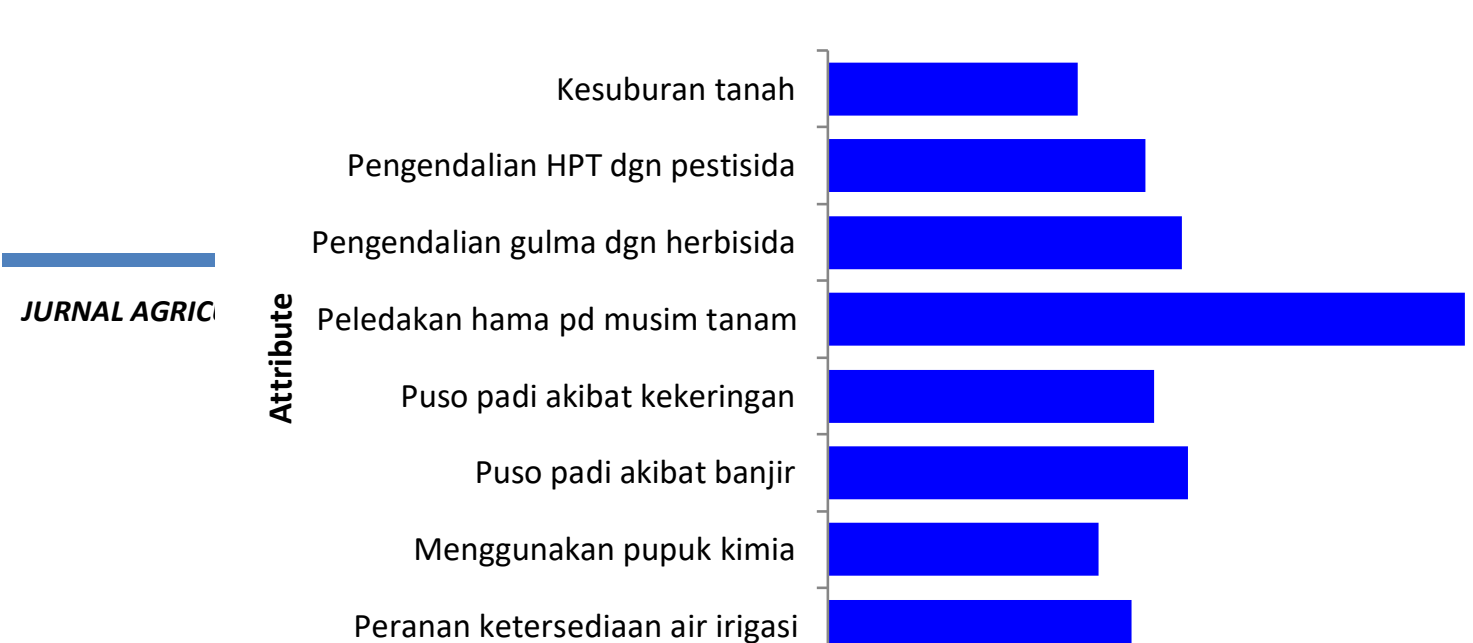


Gambar 3.1. Sensivitas Atribut Dimensi Ekologi Penerapan Program Sekolah Lapang Pengelolaan Tanaman Terpadu di Kabupaten Musi Rawas

Dari data diagram sensivitas atribut petani sendiri. Melalui program Sekolah dimensi ekologi dalam penerapan program Lapang PHT (SLPHT) Departemen Pertanian sekolah lapang pengelolaan tanaman terpadu berhasil melatih lebih dari satu juta petani, di Kabupaten Musi Rawas, perlu mendapat khususnya untuk tanaman padi dan tanaman perhatian dan dikelola dengan baik agar nilai pangan lainnya. Hal ini tentu penting artinya indeks keberlanjutan Penerapan Program SL- dalam meningkatkan kesejahteraan petani PTT di Kabupaten Musi Rawas dimensi melalui PHT dalam praktek pertanian yang ekologi ini dimasa yang akan datang lebih baik.

meningkat lagi. Atribut pada dimensi ekologi

yang paling sensitiv yang mempengaruhi 3.2.Keberlanjutan Penerapan Program keberlanjutan Penerapan Program SL-PTT di Kabupaten Musi Rawas dapat dilihat pada Gambar 3.1. adalah peledakan hama pada saat musim tanam. Budidaya tanaman padi tidak

\section{SL-PTT di Kabupaten Musi Rawas Dimensi Teknologi}

Hasil analisis menunjukkan indeks terlepas dari hama dan penyakit, hama dan keberlanjutan Penerapan Program SL-PTT penyakit merupakan salah satu faktor yang dimensi teknologi di tingkat Kabupaten mempengaruhi keberhasilan dalam upaya adalah 73.25 dengan kategori cukup meningkatkan produktivitas padi, dari hasil berkelanjutan dengan atribut-atribut survey di Kabupaten Musi Rawas di tiga memberikan pengaruh terhadap keberlanjutan kecamatan sudah menerapkan pengendalian pada dimensi teknologi terdiri dari (1) hama dan penyakit secara terpadu sesuai Varietas Unggul Baru, (2) menggunakan bibit dengan anjuran program SL-PTT namun yang bermutu dan sehat, (3) menggunakan perlu ditingkatkan lagi dalam penanganan alsin pertanian (4) penanaman bibit, (5) hama terutama beberapa elemen harus terlibat sistem tanam legowo, (6) pemupukan sesuai dan saling berkoordinasi. Pengendalian dengan dosis dan waktu, (7) penggunaan Hama Terpadu (PHT), adalah pengendalian bahan organik, (8) pengairan berselang, (9) hama dengan memanfaatkan seluruh teknik pengendalian gulma secara terpadu, (10) atau cara pengendalian hama secara harmonis Pengendalian hama terpadu, (11) waktu untuk menekan populasi hama sampai panen sudah tepat, (12) penggunaan alat dibawah ambang ekonomi. Menurut Effendy, panen, dan (13) pengelolaan pasca panen. B.S. 2009. Keberhasilan Indonesia dalam Berdasarkan hasil analisis leverage mengembangkan PHT tentu tidak terlepas keberlanjutan RAP-Program SL-PTT dapat dari peran aktif berbagai pihak, termasuk dilihat pada Gambar 3.2

\section{Leverage of Attributes}

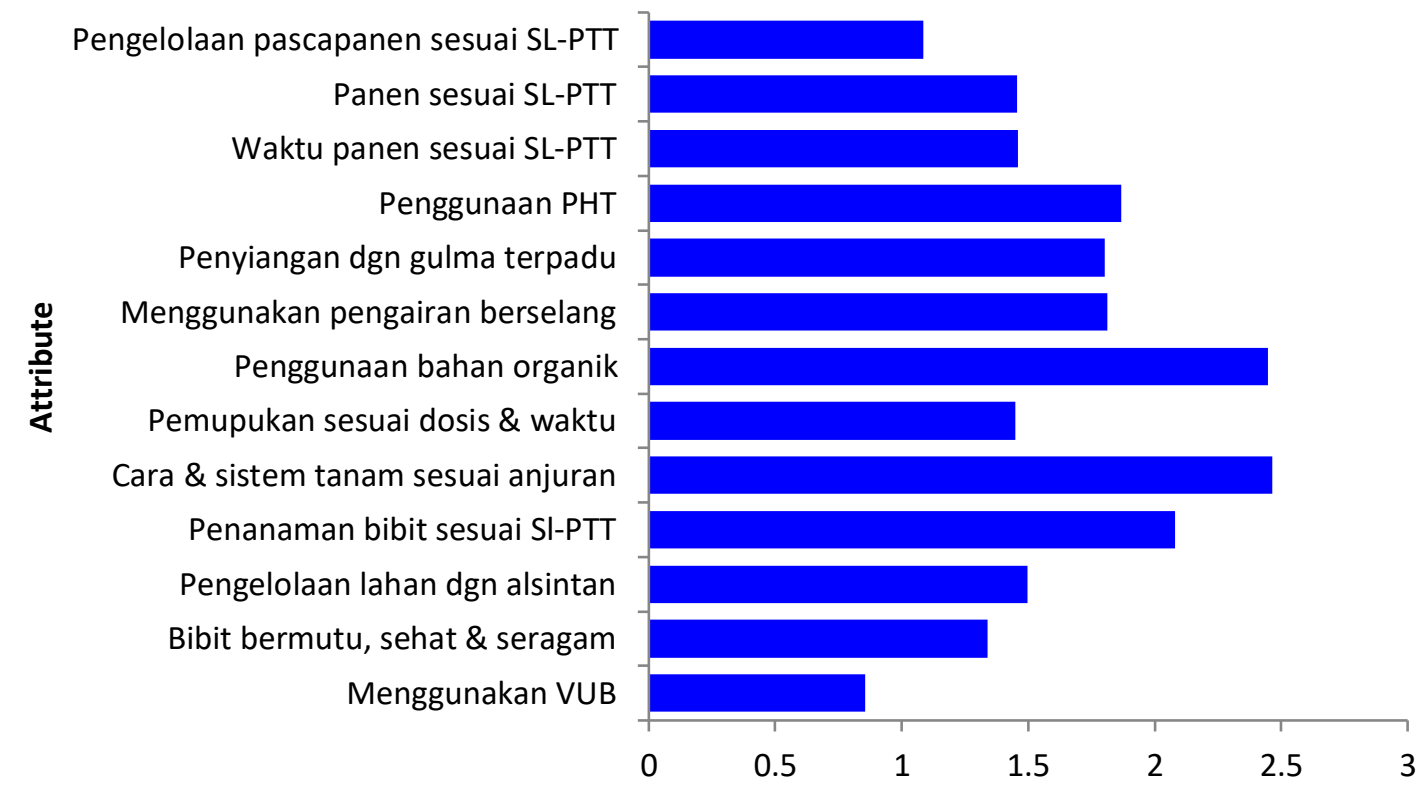

Root Mean Square Change \% in Ordination when Selected Attribute Removed (on Status scale 0 to 100) 
Gambar 3..2. Sensivitas Atribut Dimensi Teknologi Penerapan Program Sekolah Lapang Pengelolaan Tanaman Terpadu di Kabupaten Musi Rawas

Berdasarkan sensivitas atribut dimensi Tanaman Pangan, 2016). Diharapkan teknologi di Kabupaten Musi Rawas, pada selanjutnya dilakukan upaya perbaikan Gambar 3.2. penggunaan pupuk organik melalui intervensi kebijakan secara tepat pada kurang diminati di tiga kecamatan tersebut, atribut yang masih lemah.

pada saat musim tanam padi, hampir sebagian petani selalu menggunakan pupuk kimia seperti Urea, Ponska, $\mathrm{KCl}$ dan NPK, hal ini berdasarkan hasil survey dan diskusi antara peneliti, petani dan PPL, diperoleh tanggapan petani terhadap penggunaan pupuk kimia, dimana petani tidak bisa lepas dari keinginan dalam penggunaan pupuk kimia, agar tanaman mereka dapat cepat tumbuh subur dan menghasilkan setelah dipupuk menggunakan pupuk kimia. Sedangkan menggunakan pupuk organik hasilnya dinilai jauh lebih lambat responnya terhadap tanaman padi dibandingkan penggunaan pupuk kimia.

Hal ini sejalan dengan pendapat Novianto, et,al. 2020, pupuk organik kandungan haranya lebih kecil dibandingkan dengan pupuk yang berasal dari pabrik, karena sebagian besar pupuk organik terutama pupuk padat lebih fokus sebagai Badan Pusat Statistik, 2020. Data Produksi pembenah tanah yaitu memperbaiki sifat fisik, sifat kimia dan sifat biologis tanah. Selain itu hasil observasi,menurut pendapat kelompok tani di tiga kecamatan pupuk organik belum ada ketentuan khusus, seperti halnya pupuk kimia seperti memiliki manfaat dalam merangsang pertumbuhan cabang, akar Balai dan merangsang buah, disamping itu penggunaan pupuk organik lebih banyak untuk diaplikasikan pada tanaman (ton/ha) dibandingkan pupuk kimia, begitu juga dengan kandungan unsur hara pupuk organik tersedia dalam jumlah sedikit, hanya 5\% per Departemen Pertanian, 2008. Buku Pedoman ton kandungan $\mathrm{N}$ yang ada pada pupuk organik. Sistem tanam legowo juga kurang diminati oleh beberapa kelompok tani karena Direktur Jenderal Tanaman Pangan, 2012. membutuhkan tenaga kerja yang banyak dan membutuhkan benih lebih banyak. Untuk mendukung penerapan teknologi tanam jajar legowo, maka akan difasilitasi bantuan benih dan alat tanam antara lain caplak kepada petani/kelompok tani/gapoktan dalam Diektur Jenderal Tanaman Pangan. 2016. mengatasi beberapa kelemahan dalam Petunjuk Teknis Teknologi Tanam Jajar penanaman padi system jajar legowo (Dirjen

\section{BAB IV \\ KESIMPULAN}

. Hasil penelitian menunjukkan indeks keberlanjutan dimensi ekologi dengan kategori baik atau sangat berkelanjutan.

2. Berdasakan sensivitas atribut, untuk meningkatkan nilai indek keberlanjutan perlu adanya perhatian khusus dalam pengendalian hama, penggunaan bahan organik dan sistem penanaman padi dalam upaya meningkatkan produksi padi.

\section{DAFTAR PUSTAKA}

Tanaman Padi

https://www.bps.go.id/indicator/53/149

8/1/luas-panen-produksi-danproduktivitas-padi-menurutprovinsi.html

Pengkajian Teknologi Pertanaian Bengkulu, 2011. Kumpulan Makalah Penerapan Inovasi Teknologi. Balai Pengkajian Teknologi Pertanaian. Bengkulu. Umum SL-PTT Padi.

Petunjuk Teknis Pelaksanaan SL PTT. http://tanamanpangan.pertanian.go.id/fil es/Pednis_SLPTT2012.pdf (diakses pada tanggal 07 November 2014)

Petunjuk Teknis Teknologi Tana
Legowo. Kementerian Pertanian. 
Effendy, B.S, 2009. Strategi Pengendalian Hama Terpadu Tanaman Padi Dalam Perspektif Praktek Pertanian Yang Baik (Good Agricultural Practices). Balai Thamrin, S.H. Surthatjo, C.Herison, S. Besar Penelitian Tanaman Padi, Pengembangan Inovasi Pertanian 2(1), 2009:65-78. Subang.

Novianto, N., Effendy, I., \& Aminurohman, A. (2020). Respon Pertumbuhan dan Hasil Tanaman Sawi (Brassica junceea L.) Terhadap Pupuk Organik Cair Hasil Fermentasi Sabut Kelapa. Agroteknika, 3(1), 35-41.

Nurmalina, R. 2007. Model Ketersediaan Beras Yang Berkelanjutan Untuk

\section{Mendukung Ketahanan Pangan} Nasional. Disertasi Sekolah Pascasarjana. Institut Pertanian Bogor.

Sabihan, 2007. Analisis Keberlanjutan Wilayah Perbatasan Kalimantan Barat Malaysia untuk Pengembangan Agropolitan (studi kasus Kecamatan Dekat Perbatasan Kabupaten Bengkayang). Jurnal Agro Ekonomi, Volume 25 No. 2 Oktober 2007; 103 124

Yanuarto. R. 2011. Dampak program sekolah lapang pengelolaan tanaman terpadu (SL-PTT) terhadap pendapatan petani padi di Kecamatan 